\title{
Integración de las TIC en docentes del POLISAL, UNAN-Managua
}

MSc. Wilber Antonio Delgado Rocha Docente del Departamento de Enfermería UNAN-MANAGUA, POLISAL wildelg@yahoo.es

Palabras clave: TIC, brecha digital, nivel de integración de las TIC, estrategias para integrar las TIC, uso de las TIC en la enseñanza.

\section{RESUMEN}

E objetivo de esta investigación fue analizar el nivel de integración de las TIC por parte de los docentes universitarios del Instituto Politécnico de la Salud (POLISAL) en el proceso de enseñanza, para ello se realizó un estudio descriptivo, correlacional y analítico. Se examinaron los datos respecto a las características sociodemográficas y laborales, TIC, que usan los docentes en la enseñanza, estrategias institucionales para integrar las TIC en el POLISAL, actitud de los docentes y nivel de integración de las TIC a nivel de cátedra. El análisis estadístico fue descriptivo y analítico con la prueba de correlación no paramétrica, Tau-C de Kendall. Entre los principales resultados se obtuvo que la actitud de los docentes hacia la integración de las TIC es recesiva, pero positiva. En cuanto al nivel de integración de las TIC, el 58\% de los docentes se encuentran en el nivel de adaptación y el 36\% de los docentes, en el nivel de adopción.

\section{INTRODUCCIÓN}

Las investigaciones acerca del uso de las Tecnologías de la Información y Comunicación (TIC) en la educación no es una novedad, de hecho desde la década de los setenta se ha realizado diversidad de investigaciones acerca de la integración curricular de las TIC. Los resultados de las investigaciones refieren, que el proceso de integración curricular de las TIC es lento y que en el camino se pasa por una serie de etapas. Como refiere Marchesi (2007), en el contexto latinoamericano, "no basta con dotar de equipos de cómputo o servicios digitales a los centros educativos" (citado por Barriga, 2012, p.133). Asimismo, concuerda con Moreno y Pozo (2008) quienes afirman que, tampoco es suficiente la adaptación o importación de las formas de enseñanza y contenidos habituales, sino que es necesaria una verdadera innovación en el currículo y la enseñanza, si se busca congruencia con el concepto de calidad educativa.

Los estudios de integración de las TIC han sido desarrollados desde muchas perspectivas pero la más conocida a nivel latinoamericano es la clasificación desarrollada por Sandholtz, Ringstaff y Dwyer, (1997, p.3) con base a los estudios realizados por el proyecto Apple Classrooms of Tomorrow (1985), en el que se definen cinco niveles para la integración de las TIC en las cátedras de los 
docentes: acceso, adopción, adaptación, apropiación e invención. Retomando la clasificación anterior, en este estudio se evaluó el nivel de integración de las TIC en la cátedra de docentes del POLISAL UNAN-Managua debido a que estos hacen uso de las tecnologías, pero no fueron capacitados en el uso pedagógico de las TIC. Los resultados del estudio sirven de línea de base para elaborar políticas institucionales que conlleven a las TIC a la debida integración curricular con los procesos de enseñanza-aprendizaje, así como identificar debilidades y necesidades que permitirán planificar las decisiones adecuadas para que los docentes fortalezcan el uso de las tecnologías educativas.

El estudio tiene por objetivo general, analizar el nivel de integración de las TIC por parte de los docentes del POLISAL durante el proceso de enseñanza, desglosando este en los siguientes objetivos específicos: describir las condiciones sociodemográficos y laborales de los docentes, identificar las TIC que utilizan los docentes del POLISAL durante el proceso enseñanza, describir las estrategias empleadas por las autoridades para integrar las TIC, identificar las actitudes de los docentes del POLISAL hacia la integración de las TIC, determinar el nivel de integración de las TIC (uso, manejo y actitudes) de los docentes e identificar el grado de correlación entre la actitud de los docentes y el nivel de integración de las TIC.

\section{MATERIAL Y MÉTODO}

El estudio tiene un enfoque mixto, según el diseño metodológico. El tipo de estudio es analítico y de acuerdo al método de estudio es no experimental. De acuerdo al tiempo de ocurrencia de los hechos y registro de la información, el estudio es prospectivo, y según el período y secuencia del estudio es de corte transversal. Conforme a la clasificación de Hernández, Fernández y Baptista (2010), el tipo de estudio es Correlacional.

El área de estudio fue el Instituto Politécnico de la Salud "Luis Felipe Moncada", ubicado en el costado sur de la UNAN-Managua, al norte de Villa Fontana. La población en estudio estuvo conformada por los 52 docentes que laboran en los Departamentos de Enfermería, Bioanálisis Clínico, Anestesia y Reanimación, Fisioterapia y Nutrición. Desde el enfoque cuantitativo, no se calcula muestra ni se realiza técnica de muestreo porque se trabajó con todos los docentes que laboran en el POLISAL y que cumplieron con los criterios de inclusión. Desde el enfoque cualitativo, se realizó el muestreo por conveniencia, que consta en seleccionar sujetos de estudio que tienen información importante.

Los instrumentos fueron el cuestionario administrado a docentes, la entrevista semi-estructurada que se les aplicó al Director del POLISAL y tres directores de los Departamentos y el grupo focal que se aplicó a algunos docentes. El cuestionario es una adaptación del test estandarizado para medir integración de las TIC por parte de docentes en el que se tomó en cuenta el uso, dominio y actitudes de los docentes hacia las TIC en el proceso de enseñanza-aprendizaje (Orantes, 2009 y Nóbile, 2014). El cual fue validado por dos expertos en tecnología educativa, asimismo se midió el índice de consistencia interna con el alfa de Cronbash, dando un coeficiente igual a 0.869 el cual se considera un valor de consistencia interno adecuado.

Los datos generados del cuestionario fueron analizados con el programa SPSS V.23, en el que se utilizó estadística descriptiva, como la tabla de distribución de datos y las medidas de tendencia central. También se utilizó la estadística inferencial en el que se usó la prueba Tau C de Kendall para 
evaluar la correlación entre las variables actitud de los docentes y nivel de integración de las TIC. Para el análisis cualitativo de las entrevistas y grupo focal, se utilizó el procesador de texto Word, en el que se crearon códigos descriptivos, analíticos y luego categorías (Gibbs, 2012, pp.66-74), para luego realizar los informes. Para agregar rigor, amplitud y profundidad a la investigación, se realizó la triangulación metodológica debido a que se usa cuando se aplican múltiples métodos, materiales empíricos, perspectivas y observadores (Álvarez-Gayou, 2003).

\section{ANÁLISIS Y DISCUSIÓN DE LOS RESULTADOS}

En cuanto a las características sociodemográficas de los docentes, los resultados indican que la edad promedio de los docentes del POLISAL es de 40 años, en los que utilizando la analogía de Prensky (2010), significa que más de la mitad de los docentes son inmigrantes digitales y por ello, nacieron antes de las tecnologías y han tenido que capacitarse en el uso de las TIC, y la otra mitad, son nativos digitales, por ello nacieron y han crecido con el avance de las tecnologías, por lo cual se les facilita el uso de estas. El sexo predominante es femenino, probablemente porque en el POLISAL se ofertan carreras de la salud (excepto medicina), y estas por tradición, se han venido ejerciendo por mujeres.

La mayoría de los docentes en estudio pertenecen al departamento de Enfermería, debido a que este departamento oferta cuatro carreras, seguido por Bioanálisis Clínico que oferta dos carreras y luego las demás. El número mínimo de horas al día dedicados a la docencia, es de dos y el máximo 14 horas. En la figura 1 se observa que el primer cuartil indica que los docentes dedican entre cuatro y seis horas al día. El segundo y tercer cuartil indican que el $75 \%$ de los docentes dedican entre seis y ocho horas al día a la docencia y el restante $25 \%$ entre ocho y diez horas. También se puede observar valores atípicos de docentes que dedican menos de dos horas y otros con valores entre 11 y 16 horas dedicadas a la docencia.

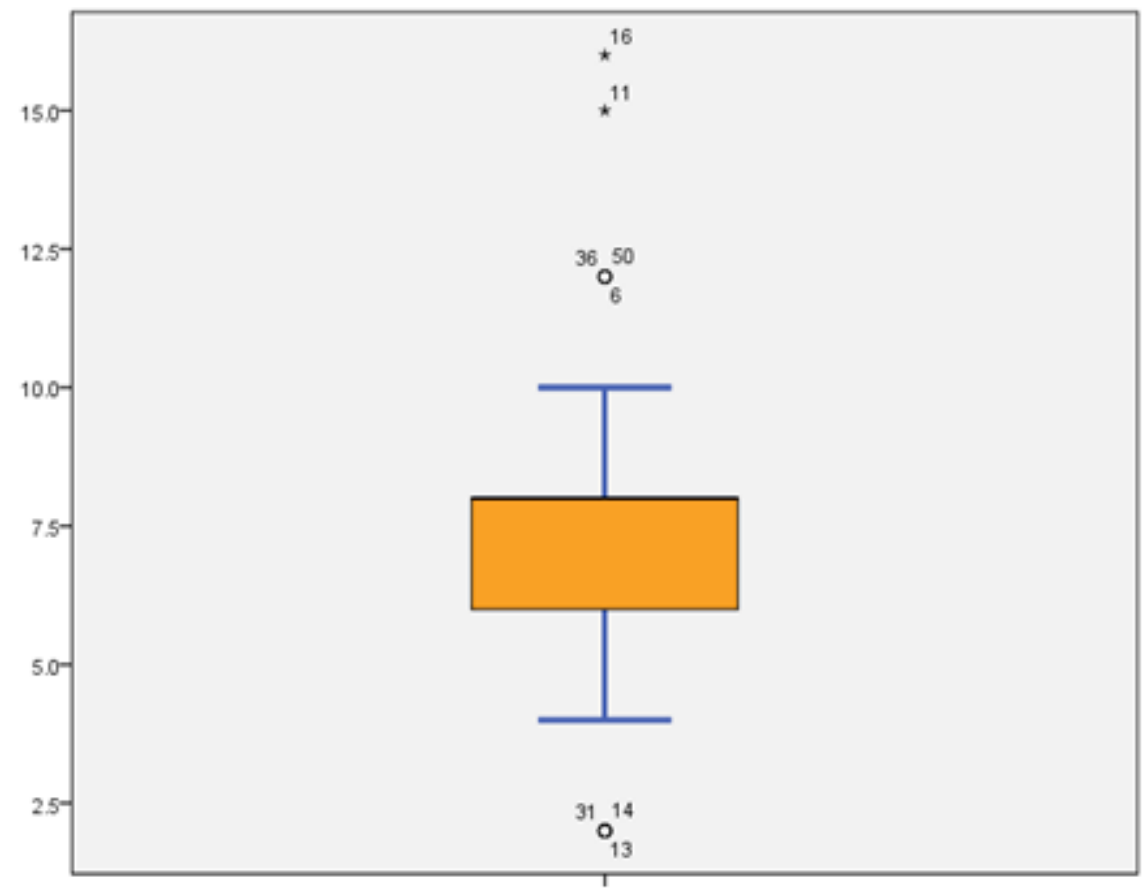

Figura 1. Número de horas al día que dedican a la docencia los docentes del POLISAL 
Desde el punto de vista de la dimensión del acceso de la brecha digital, los docentes del POLISAL tienen tres escenarios donde usan las TIC, estos son: sus cubículos, sus casas y en las aulas de clase. Sin embargo, ellos tienen acceso a una computadora con conexión a Internet solo en sus cubículos y en sus casas, pero no así en las aulas de clase, debido a que en estas se carece del servicio de Internet y muchas veces las laptop y proyectores están en mal estado, obstaculizando el proceso de enseñanza con el uso de las TIC. Contrario a lo último se puede apreciar condiciones diferentes en los estudiantes porque ellos poseen algunos dispositivos móviles como Tablet o teléfonos inteligentes con conexión a Internet y constantemente están consultando todo lo que expone el docente en el aula de clase.

Álvarez y otros (2013) declaran, que en las instituciones de educación superior con un enfoque de integración, se deben considerar armónicamente aspectos tecnológicos y pedagógicos, a tono con las políticas educativas del contexto concreto en que se integran. Lo anterior es una debilidad institucional porque no existen políticas o normativas para la integración de las TIC en la UNAN-Managua ni en el POLISAL. De hecho, hasta este momento se están construyendo. En los documentos institucionales en las que solo se mencionan el uso de las TIC, en los que se pueden mencionar es el Modelo Educativo, normativa y metodología para la planificación curricular (2011), y dentro del Plan Operativo Anual, en el que solo se menciona el uso de las TIC, como objetivos, como política y también como actividad. Sin embargo, ningún documento refiere cómo se tienen que integrar las TIC.

En la figura 2 se puede observar que el 96\% de los docentes manifiestan actitudes de acuerdo hasta muy de acuerdo hacia la integración de las TIC y solo el $4 \%$ se muestra indiferente. Sin embargo, en la entrevista al director del POLISAL y directores de departamento se evidencia que hay opiniones diferentes sobre la actitud de los docentes hacia la integración de las TIC. Entre las actitudes de los docentes hacia la integración de las TIC se mencionan positiva pero recesiva'. Orantes (2009) plantea, que las actitudes funcionan como modelos mentales, les dan a la persona una preferencia positiva o negativa sobre el objeto, una situacion con la que se está en contacto, las actitudes de los docentes pueden variar desde los que están completamente de acuerdo con las bondades hasta los que las ven como una amenaza que atenta contra el proceso de enseñanza-aprendizaje.

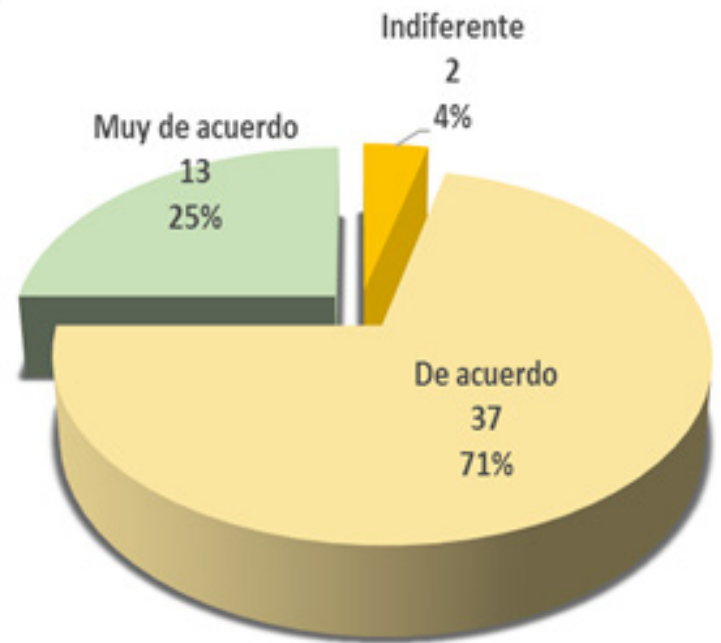

Figura 2. Actitud de los docentes hacia la integración de las TIC

1. RAE: Acción y efecto de retirarse o retroceder 
En cuanto al nivel de integración de las TIC, una parte de los docentes se encuentra en la etapa de adopción y la mayoría, en la etapa de adaptación. Estos resultados indican que los docentes están en la etapa de adopción y han desarrollado conocimientos sobre el uso de software de edición de presentaciones, arreglan algunos desperfectos en sus equipos y usan muy bien el paquete ofimático.

Los docentes que transitan en la etapa de adaptación han desarrollado conocimiento y habilidades avanzados en el paquete ofimático, edición de imágenes, correo electrónico y buscadores. Los docentes también han iniciado a producir materiales educativos con las TIC como: la creación de textos digitales, llevan control de la asistencia con la hoja de cálculo, usan blogs o grupos en redes sociales para establecer comunicación con los estudiantes, orientan investigaciones en sitios confiables y utilizan videos educativos que descargan de YouTube o ellos mismos graban para los estudiantes, utilizando el software de grabación de videos de sus teléfonos celulares. Entre las actividades que orientan a los estudiantes están: exponer en clase utilizando las TIC, usar algún software como el procesador de texto, Excel, editores de imágenes y videos para realizar tareas y realizar investigaciones con las TIC.

En cuanto a los datos obtenidos, la correlación entre la actitud y el nivel de integración de las TIC de los docentes, no hay evidencia que indique la relación entre las dos variables.

Con un $\mathbf{r}=\mathbf{- 0 . 1 0 3}$, la cual muestra una correlación negativa muy débil, y un $\mathbf{p}$-valor $\mathbf{0} \mathbf{0 . 2 8 7}$, menor que el nivel crítico establecido $\mathbf{a}=\mathbf{0} \mathbf{0 . 0 5}$. Con las evidencias de la prueba de hipótesis estadística y lo manifestado por los docentes en la entrevista y grupo focal, se concluye rechazando la hipótesis de investigación, lo que indica que la actitud de los docentes del POLISAL no está relacionada al nivel alcanzado en la integración de las TIC al proceso de enseñanza.

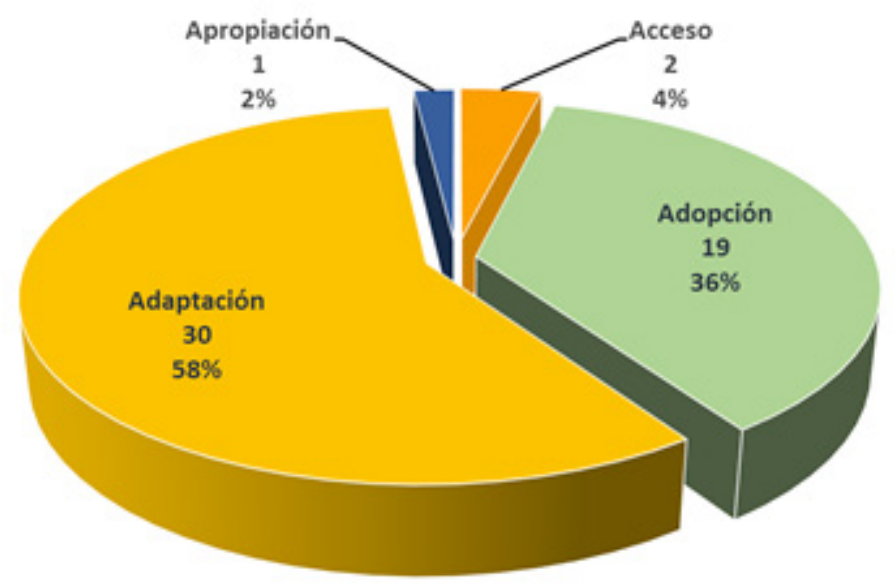

Figura 3. Nivel de integración de las TIC en la enseñanza

\section{CONCLUSIONES}

A partir de los resultados obtenidos y los hallazgos relevantes descritos en la discusión de resultados, el presente estudio arribó a las siguientes conclusiones:

a. En cuanto a las condiciones sociodemográficas y laborales, predomina el sexo femenino. La mitad de docentes son menores de 40 años y la otra mitad mayor. El nivel académico 
que prevalece es maestría. El departamento con más docentes es Enfermería, seguido de Bioanálisis Clínico y Fisioterapia. La mayoría de los docentes dedican entre cuatro y ocho horas a la docencia.

b. Los docentes tienen las condiciones adecuadas para integrar las TIC en el proceso de enseñanza en el trabajo y en sus casas, específicamente cuentan con computadoras de escritorio con conexión a Internet e instaladas las aplicaciones del paquete ofimático. Se evidencia la necesidad de contar con Internet en las aulas de clase.

c. EI POLISAL no tiene una estrategia definida para la integración de las TIC. Todo lo realizan de forma empírica, aunque se menciona en el documento Modelo Educativo, Normativa y Metodología para la Planificación Curricular (2011), de la UNAN-Managua. Las capacitaciones recibidas por los docentes están enfocadas en el uso de estas herramientas tecnológicas y no en el uso pedagógico de las TIC.

d. La actitud de los docentes hacia las TIC es recesiva pero buena, lo que indica que están conscientes que se debe realizar el proceso de integración.

e. Las aplicaciones que más usan y dominan los docentes del POLISAL son las del paquete ofimático, sin embargo, utilizan grupos de las redes sociales para establecer comunicación con los estudiantes, para contestar preguntas de ellos y para grabar los procedimientos que realizan en los laboratorios. También usan las TIC para desarrollar las clases y orientan la exposición de los estudiantes con el uso de las TIC.

f. Con los datos en este estudio, según prueba de hipótesis estadística, lo referido en las entrevistas y grupo focal, se afirma que no existe relación entre la actitud de los docentes hacia las TIC y el nivel de integración.

\section{REFERENCIAS BIBLIOGRÁFICAS}

Álvarez, A., Hernández, L., Cabrera, J. \& Herrero, E. (2013). Estudio de las dimensiones de la integración de las TIC en una universidad tecnológica cubana. Obtenido de: http://rci.cujae.edu.cu/ index.php/rci/article/view/207/pdf

Álvarez-Gayou, J. (2003). Cómo hacer investigación cualitativa fundamentos y metodología. México: Paidos Educador. Obtenido de: http:// mayestra.files.wordpress.com/2013/03/ investigacic3b3n-cualitativa-juan-luisalvarez-gayou-jurgenson.pdf
Díaz-Barriga, F. A. (2012). Reformas curriculares y cambio sistémico: una articulación ausente pero necesaria para la innovación. Obtenido de: https://ries. universia.net/rt/printerFriendly/80/266

Gibbs, G. (2012). En análisis de datos cualitativos en investigación cualitativa. Madrid: EDICIONES MORATA, S.L.

Morales, A. \& Ramírez, A. (2015). Brecha digital de acceso entre profesores universitarios, de acuerdo a su disciplina. Obtenido de: http://www.labrechadigital. org/labrecha/DOCS/5997-33502-1-PB. pdf 
Nóbile, C. I. (2014). Procesos de integración de tecnologías de la información y la comunicación en instituciones de educación superior. El caso de la facultad de ciencias económicas de la universidad nacional de la plata. Obtenido de: http://sedici.unlp.edu. ar/bitstream/handle/10915/45725/ Documento_completo.pdf?sequence=3

Orantes, L. (2009). Actitudes, dominio y uso de las tecnologías de la información y la comunicación (TIC) de los docentes de las universidades privadas de El Salvador. Obtenido de Universidad Tecnológica del El Salvador.
Prensky, M. (2010). Nativos e Inmigrantes Digitales. Obtenido de: http://www. marcprensky.com/writing/PrenskyNATIVOS\%20E\%2OINMIGRANTES\%20 DIGITALES\%20(SEK).pdf

Sandholtz, J., Ringstaff, C. \& Dwyer, D. (1997). Teaching with Technology: Creating Student-Centered Classrooms, Teachers College. Obtenido de: http:// plaza.ufl.edu/gatorjlh/eportfolio/ TechnologyBookReview.pdf 